\title{
Insulin detemir
}

National Diabetes Information Clearinghouse (NDIC)

\section{Definitions}

Insulin

Defined by National Diabetes Information Clearinghouse (NDIC)

Onset

Defined by National Diabetes Information Clearinghouse (NDIC)

Peak

Defined by National Diabetes Information Clearinghouse (NDIC)

Duration

Defined by National Diabetes Information Clearinghouse (NDIC)

\section{Source}

National Diabetes Information Clearinghouse (U.S.). (2009). The diabetes dictionary. [Bethesda, Md.]: U.S. Dept. of Health and Human Services, National Institutes of Health, National Institute of Diabetes and Digestive and Kidney Diseases, National Diabetes Information Clearinghouse.

A long-acting insulin with an onset of 1 hour, no peak, and a duration of 20 to 26 hours. (Brand name: Levemir.) 